Esta revista forma parte del acervo de la Biblioteca Jurídica Virtual del Instituto de Investigaciones Jurídicas de la UNAM www.juridicas.unam.mx

http://biblio.juridicas.unam.mx/

\title{
Combatir la enfermedad, no los síntomas: tres propuestas para atacar el costo creciente de las campañas electorales en México
}

\section{Luis Carlos Ugalde*}

\section{Sumario:}

I. El problema

II. Las causas

III. Malas prácticas contables

IV. Soluciones

V. ¿Se requiere una nueva reforma electoral?

* Director general de Integralia Consultores. Fue consejero presidente del Instituto Federal Electoral entre 2003 y 2007 (luiscarlos.ugalde@integralia.com.mx). Agradezco a Gustavo Gil Ramos por su trabajo de apoyo para este artículo.

D. R. (c) 2013. Universidad Nacional Autónoma de México-Instituto de Investigaciones Jurídicas. 
El costo creciente de las campañas electorales es la mayor fuente de inequidad electoral en México. A pesar de que se modificó en 2007 la fórmula de financiamiento para reducir los montos que reciben los partidos para campañas, los candidatos gastan sumas crecientes de recursos que obtienen de diversas fuentes, muchas de ellas prohibidas por la ley. Además de causar inequidad, el elevado costo de las campañas propicia corrupción política ya que la mayoría de quienes dan dinero a campañas lo hacen en espera de algún beneficio económico futuro.

Para atacar las causas estructurales del costo creciente de la democracia electoral es necesario afectar factores extra electorales en materia hacendaria, fiscal, de medios de comunicación y aún de prácticas socioculturales como el clientelismo. Emparejar la cancha del juego requiere hoy de reformas en ámbitos no-electorales que, sin embargo, tendrían un efecto directo y global sobre las condiciones de la competencia entre candidatos y partidos. La mejor reforma electoral es hoy la reforma no-electoral.

\section{El problema}

El alto costo de las campañas electorales propicia inequidad en la competencia porque sólo algunos candidatos cuentan con los recursos suficientes para ser competitivos en una elección - sea de gobernador, legislador, presidente municipal o de la República-. Aunque no existen datos del costo real de las campañas en México, hay aproximaciones. La evidencia anecdótica sugiere que los candidatos gastan varias veces más que lo permitido por la ley. Por ejemplo, quienes compiten para ser diputados federales, cuyo tope fue de 1120000 pesos en 2012, con frecuencia sostienen que una campaña promedio en un distrito urbano cuesta entre 8 y 10 millones de pesos. Los candidatos a senadores, cuyo tope máximo varía entre 2.2 millones (Baja California Sur) y 22.4 millones (Estado de México), expresan con frecuencia que sus gastos superan en promedio los 20 millones de pesos. Quienes lo hacen para gobernador, expresan que una campaña puede costar varios cientos de millones.

Los elevados gastos de campaña contribuyen al ciclo de la corrupción gubernamental, política y administrativa que inicia cuando los 
candidatos recurren a financiamiento de fuentes empresariales, gubernamentales y de otro tipo para cubrir los gastos de sus campañas y, a cambio, ofrecen beneficios futuros: regulación favorable, permisos especiales, contratos de obra pública, entre otros.

Hay un enfoque equivocado que supone que el costo de la democracia electoral es proporcional al monto del financiamiento público que reciben los partidos. Si se reduce el dinero que el IFE entrega a éstos, dice el argumento, la democracia se hace más barata. Bajo esa lógica, hoy se podría afirmar que las campañas son menos onerosas desde el punto de vista del presupuesto público, porque en efecto se destinan menos recursos a gastos de campaña, aunque más a actividades ordinarias.

\section{Gráfica 1. Prerrogativas a partidos políticos 2006 vs 2012} (millones de pesos constantes)

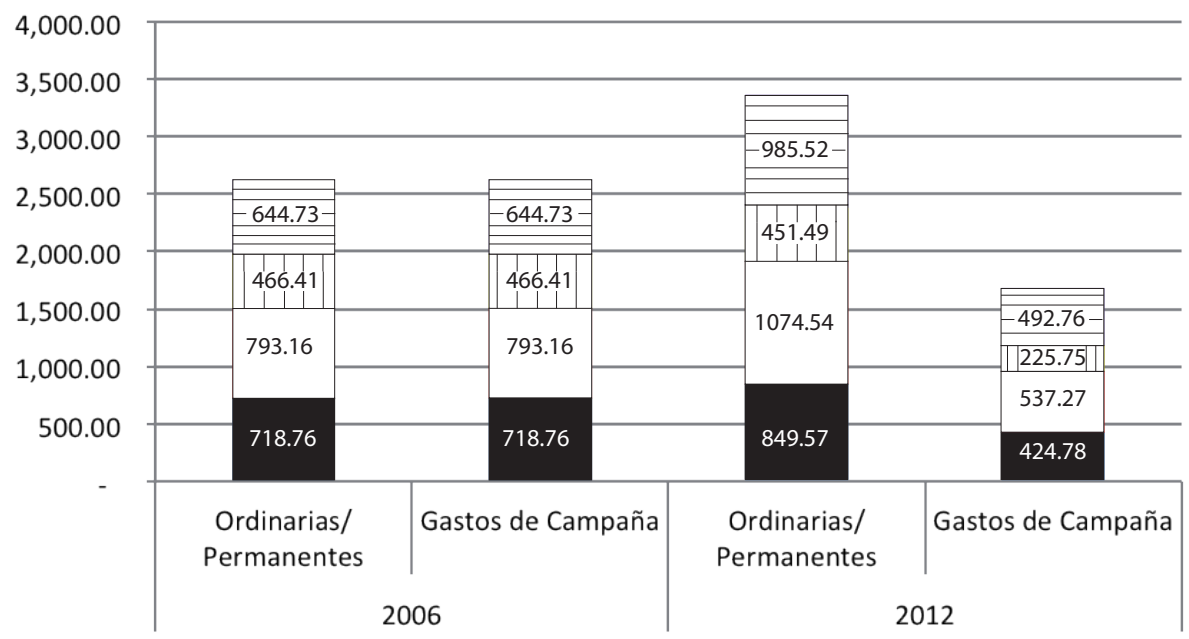

口PAN $\square$ PRI

Pero el costo de la democracia va más allá del presupuesto público a los partidos. Ciertamente a fines de los años noventa cuando se establecen las bases del modelo de financiamiento público, prácticamente el costo total de las campañas se financiaba mediante las prerrogativas que otorgaba el IFE. Pero a partir de los últimos años, sobre todo en el ámbito de las elecciones de gobernador, las prerrogativas de los partidos son sólo una parte, a veces menor, de las fuentes para pagar campañas políticas. 


\section{Diagrama 1}

Fuentes de financiamiento a los partidos políticos

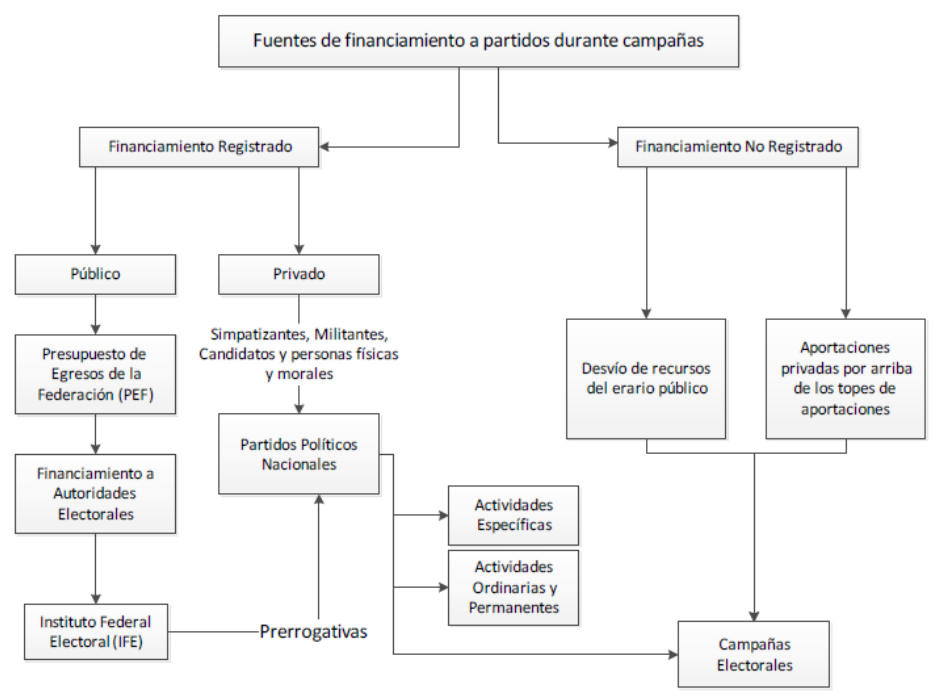

Fuente: elaboración propia.

Como se observa en el diagrama anterior, las prerrogativas que da el IFE a los partidos son una de las fuentes de financiamiento de las campañas, pero no la única. Estos pueden recibir fondos privados de forma legal, mediante aportaciones de militantes y simpatizantes y otros rendimientos, siempre y cuando se cumpla el principio de que el financiamiento público prevalezca sobre el privado. Cada vez más, sin embargo, los recursos privados y no registrados superan a aquellos del financiamiento público, aunque no existen datos (obviamente) sobre la cuantía del financiamiento no registrado que proviene de fuentes diversas: recursos líquidos que entregan empresarios o que provienen del desvío de recursos públicos, donaciones en especie, triangulaciones de una empresa que paga un servicio para ser brindado a un candidato o partido, entre otros. 


\section{Las causas}

Hay dos causas estructurales que han aumentado el costo de las campañas electorales: las prácticas de movilización del voto y de clientelismo electoral y el pago para tener cobertura noticiosa de los medios de comunicación.

El clientelismo electoral se volvió un tema álgido durante la elección de 2012 debido a las acusaciones que hizo el candidato Andrés Manuel López Obrador de que el PRI habría recurrido a prácticas masivas de "compra del voto" para ganar la elección. El clientelismo es un intercambio, a veces coaccionado pero con frecuencia voluntario, entre los partidos y sus candidatos que ofrecen regalos, dinero y beneficios futuros por un lado, y grupos sociales organizados o ciudadanos en lo individual que dan su voto o la promesa de éste a cambio de disfrutar de esos bienes materiales, por el otro. Así como el condicionamiento del voto es un delito y refleja el abuso del poder por parte de funcionarios públicos, el fenómeno de la llamada compra del voto es voluntario y es incluso demandado por segmentos de la población en muchas partes del país. De tal forma que es un intercambio en el cual ejércitos de "vendedores" de votos buscan a candidatos cada vez que hay procesos electorales para hacer un intercambio mutuamente benéfico. Esto está ocurriendo cada vez más y está generando una industria del intercambio que no se soluciona con multas ni con amenazas de cárcel —se trata de un fenómeno histórico y cultural—.

Diagrama 2

Modalidades del clientelismo electoral

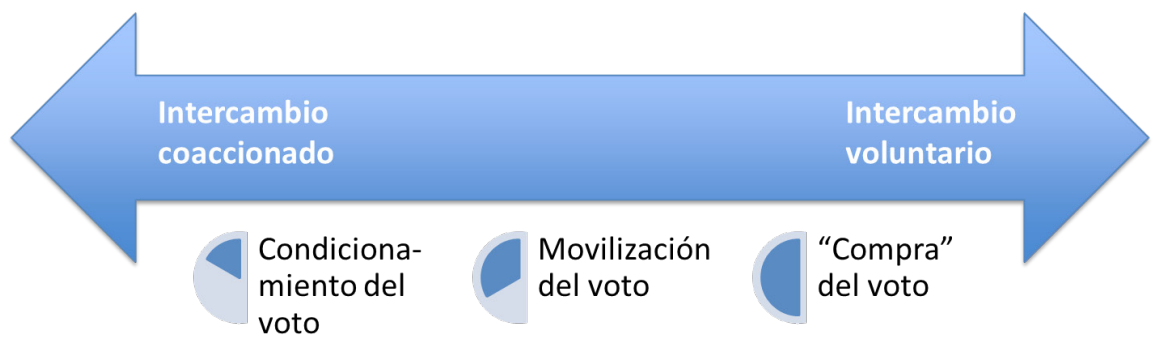

Fuente: elaboración propia. 
Aunque se carece de indicadores acerca de la incidencia del clientelismo electoral sobre el comportamiento de los votantes, lo cierto es que el intento de movilizar el voto requiere sumas enormes de recursos líquidos. Independientemente de la eficacia de los intentos que realizan los partidos para "comprar" votos, su instrumentación encarece las campañas.

El otro fenómeno que contribuye a encarecer el costo de la democracia es el pago que en ocasiones se realiza para tener cobertura noticiosa o entrevistas en algunos medios de comunicación. Se ha dicho que la reforma de 2007 generó equidad en el acceso a los medios al hacer gratuitos los spots de radio y televisión para los partidos y candidatos. Pero el fenómeno de la cobertura noticiosa pagada se ha expandido no solo en medios electrónicos sino cada vez más en la prensa local. Por ejemplo, algunos medios, sobre todo locales, exigen a los candidatos firmar "convenios de publicidad" para dar cobertura a sus campañas. En el caso de los medios electrónicos, muchas entrevistas son pagadas y existen tarifas preestablecidas. De tal forma que las prácticas para acceder a los medios requieren sumas crecientes de dinero que no es reportado a la autoridad porque se trata de actos ilegales y porque a veces son pagados por algún gobierno o por particulares o empresas mercantiles.

La práctica de algunos medios de comunicación de "cobrar" la cobertura noticiosa es sólo la continuación de la costumbre de muchos medios de vivir de la publicidad oficial, como ocurrió durante buena parte del siglo XX. La práctica de los gobiernos en México de adquirir sumas millonarias de publicidad oficial en radio, televisión y prensa ha incentivado que algunos de éstos se vuelvan cazadores de presupuesto en lugar de buscadores de lectores. Entre más dinero reciben los medios de los políticos, más adicción se genera y más exigen para cubrir campañas. Se trata de un círculo perverso en donde la calidad del periodismo o las necesidades y deseos de los lectores son secundarios.

El costo de acceso a los medios de comunicación no se reguló correctamente en 2007 al prohibir la compra de spots. Incluso, es probable que se haya agravado el problema porque muchos políticos han encontrado que ante la imposibilidad de pagar publicidad de forma abierta, la única vía para ser "famoso" es mediante mercados paralelos no registrados que a veces cuestan más. 


\section{Malas prácticas contables}

El problema del costo creciente de las campañas por encima de los topes que establece la ley propicia dos malas prácticas contables: financiamiento de campañas no registrado y gasto no reportado por los partidos políticos. Aunque no existen datos del financiamiento no registrado, la evidencia anecdótica sugiere que es un fenómeno estructural que involucra a candidatos de todos los partidos - desde aquellos que aspiran a ser presidentes municipales, diputados, senadores, gobernadores y jefes del Ejecutivo-. El modelo de financiamiento público de los años noventa no ha contribuido a evitar que el dinero privado sin registro fluya a las campañas. De hecho estamos en el peor de los mundos porque el Estado mexicano da cada vez más dinero a los partidos, pero en lugar de que esto detenga la adicción por el dinero privado, sólo ha estimulado una inflación de la industria electoral que ha estimulado más dinero de fuentes no registradas, de tal forma que tenemos mucho dinero público pero también mucho de otras fuentes.

Como hay financiamiento que no se registra porque viola preceptos legales por su monto y por sus fuentes, entonces su ejercicio tampoco se reporta a la autoridad. Evidencia anecdótica sugiere que en elecciones de gobernador, por ejemplo, se rebasa el tope de gastos de campaña varias veces, aunque se reporta lo necesario para "cumplir" formalmente con la ley. En promedio, el tope de gasto en elecciones de gobernador ronda los 60 millones de pesos; sin embargo, la evidencia anecdótica sugiere que se pueden gastar en promedio entre cinco y diez veces esa cifra. Si ser competitivo en una elección de gobernador requiere erogar algunos cientos de millones de pesos, gran parte de esos recursos se obtienen de fuentes no registradas y, con frecuencia, el ganador de una gubernatura recompensa a sus donadores con contratos de obra pública y adquisiciones, con regulación y permisos, entre otros. 
Tabla 1. Tope máximo de gastos de campaña, 2010-2012

(pesos)

\begin{tabular}{cc}
\hline Diputados federales & 1120373.61 \\
\hline Promedio gobernadores $^{*}$ & 61310261.48 \\
\hline
\end{tabular}

*Se promedió el gasto máximo de cuatro entidades: Estado de México (lista nominal más grande); Coahuila y Sinaloa (listas nominales promedio); y Baja California Sur (lista nominal más baja).

Fuentes: Instituto Federal Electoral, Instituto Electoral del Estado de México, Consejo Estatal Electoral de Sinaloa e Instituto Electoral de Baja California Sur.

Dos elementos facilitan no reportar ciertos rubros de gasto de una campaña: por un lado, la facilidad para disimular el costo real de los eventos; por otro, ocultar algunos gastos no observables. Hay eventos masivos que cuestan millones de pesos, que incluyen desde la renta del lugar, el mobiliario como sillas y mesas, la publicidad, los regalos a los asistentes, la comida y bebida, la música ambiental y el costo del transporte. Es fácil que algunos candidatos reporten sólo una parte de los gastos "reales" mediante una contabilidad doble sin que la autoridad electoral cuente con la capacidad para corroborar esa información. Por otra parte, hay muchos gastos no observables como aquel que se destina a la movilización electoral — lo que se llama el Día D-. Esta puede costar decenas o centenas de millones de pesos, la mayor parte en efectivo porque se destina a pagar a movilizadores del voto $y$ a operadores de campo.

\section{Soluciones}

Atacar el problema de los altos costos de las campañas electorales requiere diversas medidas. Aquí propongo tres: a) combatir la cobertura noticiosa pagada en medios de comunicación y dificultar el uso de efectivo para pagar estrategias de clientelismo electoral; $b$ ) dificultar la simulación del registro tanto de los ingresos como de los gastos, y c) hacer más difícil que un gobernante, una vez en el cargo, pueda retribuir a quienes le donaron recursos durante su campaña. Reducir el costo de las campañas no es un asunto ni de moral pública ni tampoco de fiscalización ni de multas: lo que se requiere es reducir los 
requerimientos financieros para ser competitivo en una campaña y reducir los incentivos económicos para que un donante dé dinero a una campaña a cambio de un beneficio futuro.

En el caso del pago de cobertura mediática, hay dos vías para disuadir el fenómeno. Por una parte, propiciar mayor competencia en la industria de medios electrónicos que limite la fuerza de aquellos con más presencia de mercado y evite que su influencia sea determinante para "construir" popularidad o ganar campañas. Por otra parte, contribuir a que los medios vivan de sus lectores, radioescuchas o televidentes, en lugar de que sean adictos a los presupuestos públicos. Cuando los gobiernos destinan sumas crecientes de dinero para publicidad oficial, se estimula una industria que vive de cabildear rentas gubernamentales en lugar de buscar satisfacer a su público. Se requiere eliminar las partidas presupuestales de publicidad oficial, para obligar a que los medios vivan de sus lectores, con excepción de las campañas de salud y de seguridad pública. El cobro de la cobertura noticiosa durante las campañas es sólo una derivación de la dependencia que muchos medios de comunicación han desarrollado respecto al dinero gubernamental. Una vía para romper esa dependencia es reducir drásticamente el presupuesto para medios de comunicación de tal forma que se altere su lógica de operación: en lugar de buscar presupuestos, los medios deben buscar lectores o televidentes.

El otro fenómeno que ha encarecido las campañas electorales es el clientelismo y su combate es aún más complejo porque se trata de un acto voluntario con raíces históricas que no se soluciona con castigos. Hay voces que sugieren que se establezcan penas para delitos de pagos de dádivas o de movilización de electores. Sin embargo, la persecución de esos delitos requiere que haya denuncia de parte y son los propios "vendedores" de votos los menos interesados en combatir ese fenómeno. Por lo tanto, la vía punitiva es ineficaz para combatir ese mal. Es más viable recurrir a campañas informativas para reducir la eficacia del clientelismo electoral - "tu voto es secreto" - que intentar la vía sancionatoria. Por otra parte, deben reducirse los canales para erogar dinero en efectivo durante las campañas porque ese es el medio de pago a los operadores de campo.

Con respecto a la simulación en el registro de los ingresos y los gastos, a fines de 2012 ocurrieron algunas reformas no electorales que tendrán un impacto favorable en la transparencia de las finanzas de las campañas. Por una parte, la reforma a la ley de transparencia que 
hace de los sindicatos sujetos obligados. Ello significa menor margen para que éstos canalicen recursos a partidos y campañas - debe recordarse que en 2000 el Sindicato de Trabajadores Petroleros de la República Mexicana (STPRM) habría canalizado a la campaña presidencial del PRI alrededor de 500 millones de pesos. También se ha reiterado que el Sindicato Nacional de Trabajadores de la Educación (SNTE) habría destinado sumas significativas de dinero para movilizar el voto en las elecciones presidenciales de 2006 y 2012 sin que se sepa si tales señalamientos son veraces. Por otra parte, la reforma a la Ley de Contabilidad Gubernamental que aumenta las obligaciones de transparencia a los gobiernos federal, estatales y municipales y con ello reduce el margen para el desvío de recursos públicos hacia campañas electorales.

Sin embargo, el asunto medular para combatir el costo creciente de las campañas se refiere a dificultar las prácticas de financiamiento ilegal. Existen dos vías. Por una parte, dado que la forma más común para retribuir a quienes donan recursos a una campaña es mediante adjudicaciones directas de contratos de obra pública o de adquisiciones, o bien, mediante la manipulación de las bases de licitación para favorecer a ciertos proveedores o constructores, se debe realizar una reingeniería de esos procesos de licitación para dificultar la posibilidad de que un donante ilegal pueda obtener un premio futuro. Desconectar la donación hoy de un posible pago futuro es la manera eficaz para disuadir esas donaciones.

Por otra parte, debe fortalecerse la fiscalización de las haciendas locales. El desvío de recursos públicos es una práctica que existe en muchos gobiernos locales en México (mediante triangulaciones, reasignaciones entre partidas, inflación de contratos de obra pública) y generan bolsas que son canalizadas a campañas políticas. La construcción de un sistema nacional de fiscalización, que ha sido propuesto por la Auditoría Superior de la Federación, es uno de los caminos más certeros para dificultar el uso de recursos públicos para fines electorales.

\section{V. ¿Se requiere una nueva reforma electoral?}

Desafortunadamente sí, porque persisten problemas estructurales que han encarecido el costo de las campañas en México y con ello detona- 
do estímulos para la corrupción. La ley electoral en México tiene dos problemas: con frecuencia ataca los síntomas, no las causas de los problemas, y lo hace con un enfoque sobrerregulatorio y punitivo. Atacar los síntomas en lugar de la enfermedad sólo prolonga los problemas, aunque da la sensación de que se combaten. Por ejemplo, la ley prohíbe las campañas negativas (una manifestación) en lugar de propiciar la veracidad de la propaganda política y una cultura más vigorosa del debate público. Se redujeron los montos de financiamiento a campañas, así como los topes máximos de gasto, como medidas para "abaratar" el costo de la democracia electoral, pero sin atacar las causas del costo creciente de las campañas en México. En 2003 - frente al malestar por el abuso del financiamiento público por parte de algunos partidos, sobre todo pequeños - se duplicaron los requisitos numéricos para formarlos sin atacar el problema de la fórmula para financiarlos ni el problema del clientelismo que subyace la organización de partidos en México. En estos tres casos, se hicieron cambios en la epidermis sin atacar los problemas de fondo y hoy tenemos campañas de denuesto, más caras y persisten algunos partidos sin representatividad.

Además de que la ley electoral no ataca muchos problemas de fondo, hay un problema de sobrerregulación que está generando una industria del litigio sin que se resuelvan los problemas de fondo. Tenemos algunas normas ineficaces y un enfoque punitivo que supone que con castigos se puede modificar el comportamiento de los actores. Por ejemplo, desde hace más de una década el IFE impone sanciones de decenas e incluso centenas de millones de pesos a los partidos políticos - notablemente dos: la multa histórica al PRI por mil millones por el caso "Pemexgate" en 2003, y aquella derivada del caso "Amigos de Fox" impuesta al PAN y al Partido Verde por 540 millones de pesos-. Sin embargo, estas sumas cuantiosas contrastan con lo poco que ha cambiado el comportamiento de los actores: pagan multas pero algunos siguen evadiendo el cumplimiento de la ley, según las propias quejas que presentan los partidos políticos.

Parece una obviedad pero en ocasiones se hacen reformas sin saber el propósito con claridad. Una reforma electoral puede tener diversos fines. La equidad es uno de ellos; la disminución del costo de las campañas es otro; la libertad de expresión y asociación es otro más. Otro podría ser propiciar que haya acatamiento del resultado de las contiendas. O bien, podría sugerirse que el fin de una reforma electoral 
sea que el sistema de asignación y distribución de los cargos públicos contribuya al funcionamiento y eficacia del gobierno.

Así como en 1996 hubo claridad sobre el fin que se perseguía en la reforma electoral de aquel año - autonomía para la autoridad electoral como instrumento para construir confianza ciudadana- en la discusión de la última reforma faltó consenso de los fines: ¿equidad?, ¿reducir costo de las campañas?, ¿solventar conflictos políticos derivados de la elección de 2006?, ¿estabilidad política? Por ello un asunto medular de una nueva reforma electoral es definir con claridad su propósito central. En mi opinión, este debería ser el de reducir los costos crecientes de las campañas. Eso poco tiene que ver con los montos de financiamiento público y mucho con las causas estructurales del costo creciente de la industria y la facilidad para financiar de manera ilegal las campañas. Lograrlo poco tiene que ver con la materia electoral y mucho con asuntos en materia de licitaciones, contabilidad gubernamental y medios de comunicación. Por eso la mejor reforma electoral para atacar el costo creciente de las campañas es la reforma no-electoral. 